\title{
Erratum to: Morphological Variability of Nitraria Species in Central and Southern Kazakhstan
}

\author{
E. V. Banaev ${ }^{a, *}$, M. A. Tomoshevich ${ }^{a}$, and T. A. Ak-Lama ${ }^{a, b}$ \\ ${ }^{a}$ Central Siberian Botanical Garden, Siberian Branch, Russian Academy of Sciences, Novosibirsk, 630090 Russia \\ ${ }^{b}$ Tyva Scientific Center, Kyzyl, 667000 Russia \\ *e-mail: alnus2005@mail.ru
}

Received September 20, 2021; revised September 20, 2021; accepted September 20, 2021

DOI: $10.1134 / \mathrm{S} 1995425521050188$

The article "Morphological Variability of Nitraria Species in Central and Southern Kazakhstan", written by E. V. Banaev, M. A. Tomoshevich, and T. A. AkLama, was originally published electronically in Springer-Link on 25 June 2021 without Open Access. After publication in volume 14, issue 3, pages 255-268 the authors decided to make the article an Open Access publication. Therefore, the copyright of the article has been changed to (C) The Author(s) 2021 and the article is forthwith distributed under the terms of a Creative
Commons Attribution 4.0 International License (http://creativecommons.org/licenses/by/4.0/, CC BY), which permits use, duplication, adaptation, distribution and reproduction of a work in any medium or format, as long as you cite the original author(s) and publication source, provide a link to the Creative Commons license, and indicate if changes were made.

The original article can be found online at https://doi.org/10.1134/S1995425521030021 